\title{
The Analysis of Commercial Banks Finance Mode to Small-Sized Import E-Commerce Enterprises Under Uncertain Demand
}

\author{
Zhao Shuangling $^{\mathrm{a}}$, Cao Guohua ${ }^{\mathrm{b}}$, Zhang Xuanxuan ${ }^{\mathrm{c}}$ \\ Economics and Business Administration, Chongqing University. Chongqing, China

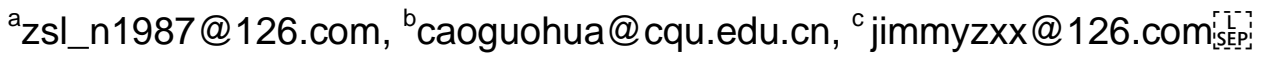 \\ zsl_n1987@126.com
}

Key words: Cross-Border E-commerce; Newsboy Model; Goods Pledge; Government Credit.

\begin{abstract}
Based on the overseas online shopping is so hot and Small-Sized Enterprises were difficult to financing nowadays, aimed at the problem that difficult to finance caused by the asymmetric information between commercial banks and import e-commerce enterprises. Summarized two ways that small-sized import e-commerce enterprises adopt goods stock pledge and the government trust to get financing from commercial banks. Used the newsboy model under uncertain demand situation, analyzed the stock decision of import of e-commerce enterprises and calculate the financing critical point of default. Compared advantages and disadvantages of two financing modes. Inferred the influence of the financing model choosing by the membership fee and government guaranty. We got two conclusions that first, import retail e-commerce enterprises would default when the market demand is less than a certain critical value; enterprises' decisions were only related to the amount of stock instead of market demand when market demand was greater than another certain critical value. Second, import retail enterprises would choose government credit financing while membership fee was less than a certain critical value. Third, government credit financing mode was more beneficial to commercial banks while government funding was greater than a certain critical value. Finally, conclusions were verified by numerical simulation. Provided a new way to solve the problem that small-sized import e-commerce enterprises financing difficulty and expensive, commercial banks how to support the small-sized import e-commerce enterprises.
\end{abstract}

\section{需求不确定性下银行为}

\section{中小型进口电子商务企业提供融资方式的分析}

\author{
赵双玲 ${ }^{a}$, 曹国华 ${ }^{b}$, 张旋璇 ${ }^{\mathrm{c}}$ \\ 重庆大学经济与工商管理学院, 重庆, 中国 \\ azs_n1987@126.com, bcaoguohua@cqu.edu.cn, ${ }^{\mathrm{c}}$ jimmyzxx@126.com \\ zsl_n1987@126.com
}

关键词：跨境电子商务; 报童模型; 存货质押授信; 政府增信。

摘要: 在目前跨境电商发展迅速和中小企业融资难的背景下，针对中小型进口电商企业与银 行间信息不对称导致难以融资的问题, 总结了目前银行为中小进口电子商务企业提供存货质 押授信和政府增信的两种模式; 引入报童模型, 对于市场需求不明确的情况下, 通过分析进 
口电商企业的备货决策计算出融资违约临界点; 并比较了两种融资模式对企业的优劣性, 推 导出政府增信模式下企业入会费、政府出资保证金等因素对于选择融资模式的影响。结论表 明：1.市场需求量小于一定临界值的时候，进口零售电商企业会违约；大于临界值的时候， 违约决策仅与备货量有关，与市场需求无关；2.企业入会的入会费小于一定金额企业会选择 政府增信下融资；3.政府出资保证金大于一定数额的时候，银行选择政府增信模式为企业融 资更有利。通过数值模拟验证了以上结论。为缓解中小型进口电子商务企业融资难和融资贵 的难题以及银行支持进口电子商务企业发展提供了新思路。

\section{1. 引言}

21 世纪的第一个 10 年间, 电子商务的发展随着互联网的普及迅速增长。第二个 10 年以 来，随着传统外贸发展增长疲弱和“海淘”购物方式的泛滥，国务院及各相关监管部门陆续出 台了 20 余份政策文件对跨境电子商务的发展进行鼓励和规范。国内跨境电商交易总体规模、 零售交易规模及零售进口规模在 2016 年分别达到了 6.3 万亿元、 4.9 万亿元和 3054.7 亿元, 同比增幅分别为 $23.5 \% 、 14.8 \%$ 和 $47.36 \%$ 。

随着进口跨境电商的迅速发展, 企业也遇到了资金困难, 如囤货、网站建设、人力资本 投入等; 在我国这一个以银行为主导的信贷市场来说, 向银行寻求资金支持无疑成为了中小 型跨境电商企业融资的首要选择 ${ }^{[1]}$ 。但由于银企之间信息的严重不对称，银行无法对中小型 尤其是处于发展初期的跨境电商企业进行准确的风险评估, 从而很难为其提供无需担保的信 用贷款。而担保公司高昂的担保费用使得跨境电商企业薄利多销的经营模式捉襟见肘。解决 中小企业融资难的问题一直以来都是亟待解决的问题, 近年来, 众多学者也加大了对中小型 企业银行融资的关注力度 ${ }^{[2,3,4]}$ 。政府非常重视跨境电商的发展以及中小企业融资难的问题, 但我国商业银行经历了三次改革之后，政府的干预程度减轻了不少 ${ }^{[5]}$ 。各大商业银行蚌蚌欲 动试图尽早介入并占领这一发展迅速和火热的“蓝海”市场，但企业和银行间信息的不对称性 导致银行存在想介入但又怕触碰风险的矛盾 ${ }^{[3]}$ 。综上, 目前的学者对于中小企业融资难的问 题有一定的研究, 对于跨境电商的研究还较少, 对于中小进口电商银行融资的问题研究就更 少了, 因此将两方面结合起来的研究对于我国在新形势下促进外贸发展是非常有意义的。

目前，各大商业银行正不断尝试创新融资产品来缓解中小型跨境电商企业的融资难题， 具有创新意义的主要有 2 种模式: 一是存货质押授信模式, 即在保税进口模式项下, 开展保 税进口业务的境外公司将货物运至保税仓库, 接受检验检疫后准备在跨境电商平台上进行销 售。为组织下一批进货, 将上一批货物的货权质押给境内银行, 通过银行获得融资, 其中以 杭州银行的“仓储贷”，广发银行的“跨境购质押贷”，平安银行的“全程货权质押授信业务”较 为典型。在存货质押这种模式下, Douglas ${ }^{[6]}$ 从供应链流程管理入手, 首先提出并系统性的研 究了仓单质押这种能使资金在供应链中快速、有效地周转的方法, 以后对仓单质押的研究也 大多是基于此开始的。占济舟 ${ }^{[7]}$ 通过 Stackelberg 模型, 分析和比较了零售商采取商业信用及 存货质押两种融资方式的选择策略。鲁其辉 ${ }^{[8]}$ 通过 EOQ 模型对目前供应链金融下委托监管、 物流银行及统一授信三种模式的决策和期望收益条件的计算分析了制造商和物流企业参与融 资的条件。二是政府增信模式, 即成立跨境电子商务协会, 入会企业交纳一定的风险铺底资 金, 再由政府及银行注资成立风险准备金池, 这作为了一种企业违约情况下银行获取风险补 偿的“安全垫”，例如工商银行的“银政通”、兴业银行的“助保贷”、邮储银行的“银园贷”。在政 府增信模式下, Leor A Klapper ${ }^{[9]}$ 提出了通过建立信息渠道的方式降低不对称的影响, 并基于 此分析了中小企业的融资现状及改进后的建议, 结果显示通过建立信息渠道能够极大的改善 中小企业的融资难题。宋建江 ${ }^{[10]}$ 从贷款对 GDP 产出率持续下降的成因分析入手，以金融资源 为基础, 将政府引入市场参与的主体, 分析了政府增信、贷款效率及经济增长之间的关系。 汪辉等 ${ }^{[11]}$ 通过演化博亦模型, 利用微分方程稳定性原理对中小企业担保与再担保进行验证, 结果显示企业融资的难易程度与担保、再担保呈正比。那么这 2 种模式是否能够有效缓解中 
小型跨境电商企业的融资难题？企业分别在两种模式下是否具有违约的临界值? 银行在提供 这两种融资模式的时候应如何防范风险? 本文将分别对这两种模式进行剖析和阐述, 并从银 行的角度出发分别在这两种模式下推论企业的违约临界点, 银行获取利润最大化的条件等结 论, 解决信息不对称的制约, 为银行控制风险的条件下介入市场蓝海并获得收益是非常具有 理论和现实意义的。

\section{2. 采用保税仓内存货质押的信贷模型分析}

由于消费者需求随机性对于企业经营利润影响，企业在物流供应链中备货量多少的决策 对其就显得至关重要。而目前大多进口电商企业的备货策略仅仅是简单凭销售经验对市场需 求进行预期，对销路非常好的“爆品”(1进行大量备货，销路一般的商品选择性备货，缺乏系统 性和科学性的分析对消费者的随机需求, 本节引入报童模型, 通过计算不同条件下进口电子 商务企业的最有订货量和融资决策，给出参与保税仓存货质押的临界条件。

保税仓进口模式类似于一种对于进口电子商务企业的买方信贷业务, 进口电子商务企业 可将仓内货物向银行进行质押融资, 凭借与供应商的贸易合同, 发票等贸易真实性证明的单 据向银行缴纳一定数额的保证金, 待货物进入保税仓, 此时保税仓存货质押类似的转化为仓 单质押业务。银行根据进口电商企业的仓储信息决定对进口电子商务企业的贷款数额。具体 流程如图 1 所示

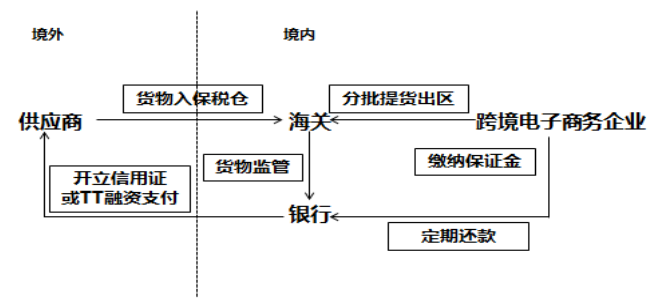

图 1 进口电商企业备货流程图

\section{1 基本假定}

\subsection{1 供应链金融模式的基本假定}

通过银行、进口电商企业、物流仓储企业三方的合作，开展供应链金融创新，银行通过 供应链条上的商品和贸易关系作为担保, 将资金注入到相对弱势的进口电商企业, 通过缓解 企业的资金瓶颈, 解决供应链失衡问题。随着供应链金融的迅速发展, 现实中出现了多种创 新模式, 例如融通仓、海陆仓、保兄仓等。总结起来, 可分为以下四种: 代客结算服务模式、 质押模式、统一授信模式和物流银行模式 ${ }^{[12]}$ 。本文主要针对供应链金融创新下质押模式中的 动态存货质押模式。银行通过与进口电商企业和物流企业三方签订的《存货质押三方合作协 议书》来约定物流企业不仅要担当仓储物流的职责, 还要提供价值评估, 货物流动的监管、 存货的保管等工作。进口电商企业存货价值有一个界限, 在贷款期间, 存货质押的价值不能 低于这个界限，但在这个模式下，客户既可以以货易货，也可以以款易货。银行在企业违约 的情况下, 委托物流企业对区内货物进行处置, 一切处置程序符合海关等监管部门的要求 2。

\subsection{2 参数的基本假定}

假设一个进口电子商务企业在单一销售季节内销售, 采购数量为 $\mathrm{q}, \mathrm{D}$ 是随机需求, $\bar{D}$ 是 平均需求, $F(x)$ 为需求分布函数, $F(x)=P(D<x), f(x)$ 为需求概率密度函数, $f(x)=F^{\prime}(x)$, 在单

\footnotetext{
通过我买网、 1 号店、京东等跨境电子商务平台以及海淘的数据汇总计算, 主要包括液态牛奶、婴幼儿奶粉、生鲜、有机食物、水果等。 来源: 《中国电商市场发展报告一2014, 电商都在做什么》

${ }^{2}$ 由于在 2016 年 4 月 8 日税改之前, 区内商品称为 “物品” 而不是 “货物”, 征收行邮税, 因此仅能做 B2C, 在质押物处置过程中会有一定 限制。税改后跨境电商保税进口项下商品和货物一样征收关税、消费税、增值税等综合税, 因此对于此类商品的监管类似于普通保税贸易 下货物的监管。
} 
位销售季节结束时未销售完的产品只能以低于成本的价格促销。采购成本为 $\mathrm{c}$ 的商品, 采购 量为 $\mathrm{q}$, 销售价格为 $\mathrm{a}$, 促销价格为 $\mathrm{b}$, 则 $\mathrm{a}>\mathrm{c}>\mathrm{b}$ 。货物的单位储存费用为 $\mathrm{s}$, 进口电子商务企 业自有初始资金为 $\mathrm{C}$, 将初始存货 $\mathrm{q}_{0}$ 作为质押向银行申请融资, 融资利率为 $\mathrm{r}$, 存款利率简 化为 $0^{3}$, 银行根据存货的进价作为参考价格给予贷款 $\mathrm{wcq}_{0}$, 获得贷款资金后企业再向供应商 采购 $\mathrm{q}\left(\mathrm{q}<\mathrm{q}_{0}\right)$ 单位的货物。

\section{2 理论模型构建}

根据上文对基本参数的假定，可分别得出在存货质押授信模式下，进口电商企业在守信 时的期望利润为: $\Pi_{1}^{E}(D)=(a-c) \min \left\{D, q_{0}+q\right\}+(b-c) \max \left\{0, q_{0}+q-D\right\}-c q(1+r)-s\left(q_{0}+q\right)$ (4), 银行的期 望利润为: $\Pi_{1}^{B}(D)=c q r$; 进口电商企业在违约时的期望利润为

$\Pi_{2}^{E}(D)=(a-c) \min \left\{\max \left[D-q_{0}, 0\right], q\right\}+(b-c) \max \left\{0, q-\max \left[D-q_{0}, 0\right]\right\}-s\left(q_{0}+q\right)$ (5)，银行的期望利润为:

$\Pi_{2}^{B}(D)=\min \left[a \min \left(D, q_{0}\right)+b \max \left(q_{0}-D, 0\right)-c q-d q_{0}, c q(1+r)\right] \oplus$

命题 1：银行提供融资为保证信贷资金安全，抵质押率须满足 $\mathrm{w}<(\mathrm{c}-\mathrm{d}) / \mathrm{c}$ 。

证明：在银行提供融资的情况下，对抵质押物打折的意义在于企业违约时处理抵质押物 的成本。

因此 $(1-w) \mathrm{cq}_{0}<\mathrm{dq} \mathrm{q}_{0}$, 因此 $\mathrm{w}<(\mathrm{c}-\mathrm{d}) / \mathrm{c}$ 。

证毕

命题 2: 在存货质押授信模式下，市场需求 $\mathrm{D}<\mathrm{D}^{\prime}$ 时，企业会选择违约，此时银行不宜提 供贷款, $D^{\prime}=\frac{c q(1+r)-(b-c) q_{0}}{(a-b)}$ 。

证明: $\Pi_{1}^{E}(D)-\Pi_{2}^{E}(D)=(a-c) D+(b-c)\left(q_{0}-D\right)-c q(1+r)<0$

$D<\frac{c q(1+r)-(b-c) q_{0}}{(a-b)}$

命题 3: 在存货质押授信模式下, 市场需求 $\mathrm{D}>\mathrm{D}$ ”时, 进口电商企业和银行双方的期望收 益与市场需求的变化无关, $D^{\prime \prime}=(1+\mathrm{w}) \mathrm{q}_{0}$ 。

证明：当 $\mathrm{D}>\mathrm{D}$ ”时，显然可得 $\Pi_{1}^{E}(D), \Pi_{2}^{E}(D), \Pi_{1}^{B}(D), \Pi_{2}^{B}(D)$ 均为定值，证毕。

命题 4: 在存货质押授信模式下, 市场需求 $D>D$ ”时，如果 $q \leq(a-c) q_{0} / c(1+r)$, 则企业会守 信; 当 $\mathrm{q}>(\mathrm{a}-\mathrm{c}) \mathrm{q}_{0} / \mathrm{c}(1+\mathrm{r})$ 时, 企业会违约。

证明：当 $\mathrm{D}>\mathrm{q}_{0}+\mathrm{q}$ 时, $\Pi_{1}^{E}(D)-\Pi_{2}^{E}(D)=(a-c) q_{0}-c q(1+r)$, 若企业选择守信, 则须 $\Pi_{1}^{E}(D)-\Pi_{2}^{E}(D) \geq 0$ ，得 $\mathrm{q} \leq(\mathrm{a}-\mathrm{c}) \mathrm{q}_{0} / \mathrm{c}(1+\mathrm{r})$ ；当 $\mathrm{q}_{0}<\mathrm{D} \leq \mathrm{q}_{0}+\mathrm{q}$ 时，同理可得 $\mathrm{q} \leq(\mathrm{a}-\mathrm{c}) \mathrm{q}_{0} / \mathrm{c}(1+\mathrm{r})$ 。因此在 $\mathrm{q}_{0}<\mathrm{D}$ 的时候，企业会在 $\mathrm{q} \leq(\mathrm{a}-\mathrm{c}) \mathrm{q}_{0} / \mathrm{c}(1+\mathrm{r})$ 时选择守信。

下面讨论 $\mathrm{q}_{0} \geq \mathrm{D}>\mathrm{D}^{\prime}$ 的时候, 此时 $\Pi_{1}^{E}(D)-\Pi_{2}^{E}(D)=(a-c) D+(b-c)\left(q_{0}-D\right)-c q(1+r)$, 若企业选择 守信, 则须 $\Pi_{1}^{E}(D)-\Pi_{2}^{E}(D) \geq 0$, 得 $\mathrm{D}>\left[\mathrm{cq}(1+\mathrm{r})-(\mathrm{b}-\mathrm{c}) \mathrm{q}_{0}\right] /(\mathrm{a}-\mathrm{b})$, 如果 $\mathrm{q}>(\mathrm{a}-\mathrm{c}) \mathrm{q}_{0} / \mathrm{c}(1+\mathrm{r})$, 则 $\mathrm{D}>\left[\mathrm{cq}(1+\mathrm{r})-(\mathrm{b}-\mathrm{c}) \mathrm{q}_{0}\right] /(\mathrm{a}-\mathrm{b})>\mathrm{q}_{0}$, 与 $\mathrm{q}_{0} \geq \mathrm{D}$ 违背, 因此 $\mathrm{q} \leq(\mathrm{a}-\mathrm{c}) \mathrm{q}_{0} / \mathrm{c}(1+\mathrm{r})$ 时, 企业会选择守信。

当 $\mathrm{q}>(\mathrm{a}-\mathrm{c}) \mathrm{q}_{0} / \mathrm{c}(1+\mathrm{r})$ 时，由于 $\mathrm{q}_{0}<\mathrm{D}$ 时，企业守信须满足 $\mathrm{q} \leq(\mathrm{a}-\mathrm{c}) \mathrm{q}_{0} / \mathrm{c}(1+\mathrm{r})$ ；在 $\mathrm{q}_{0} \geq \mathrm{D}$ 时，令 $\Pi_{11}^{E}(D)-\Pi_{12}^{E}(D)>0$, 可得 $\mathrm{D}>\left[\mathrm{cq}(1+\mathrm{r})-(\mathrm{b}-\mathrm{c}) \mathrm{q}_{0}\right] /(\mathrm{a}-\mathrm{b})$, 如果 $\mathrm{q}>(\mathrm{a}-\mathrm{c}) \mathrm{q}_{0} / \mathrm{c}(1+\mathrm{r})$, 则 $\mathrm{D}>\mathrm{q}_{0}$, 与 $\mathrm{q}_{0} \geq \mathrm{D}$ 矛盾。

证毕。

推论 1 : 在存货质押授信模式下，企业的期望利润可以表达为

(1) 当 $\mathrm{q} \leq(\mathrm{a}-\mathrm{c}) \mathrm{q}_{0} / \mathrm{c}(1+\mathrm{r})$ 时, $E\left[\Pi_{E}(D)\right]=(a-c)\left(q_{0}+q\right)-\int_{0}^{q_{0}+q}(a-b) F(x) d x-c q(1+r)-s\left(q_{0}+q\right)$, 此时企业守信的期望收益大于违约的期望收益，理性的企业会选择守信，银行可为企业

\footnotetext{
${ }^{\sqrt[3]{3}}$ 由于贷款期限不长且存款利率本来就低于贷款利率, 存款利率简化为 0 不影响本文的结论。

${ }^{\oplus}$ 具有控制权的商品数量为 $q_{0}+q$

${ }^{(5)}$ 具有控制权的商品数量为 $q$

${ }^{\oplus} d$ 为银行委托物流公司处置单位商品的费用, 且 $\Pi_{12}^{B}(D)<\Pi_{11}^{B}(D)$, 即银行不会因为处置抵质押物带来比贷款更高的期望收益。
} 
提供融资。

(2)当 $\mathrm{q}>(\mathrm{a}-\mathrm{c}) \mathrm{q}_{0} / \mathrm{c}(1+\mathrm{r})$ 时, $E\left[\Pi_{E}(D)\right]=-\int_{q_{0}}^{q_{0}+q}(a-b) F(x) d x-s\left(q_{0}+q\right)$

此时企业守信的期望收益小于违约的期望收益, 银行应加强对企业经营的关注, 防范风 险。

从推论 1 可以得出，银行对于存货质押放款后应注重贷后监管，对于企业的备货量大小 进行尽职调查, 如果备货量超过一定的临界值, 企业违约概率将上升, 此临界值不受市场需 求的影响。

推论 2: 在银行提供贷款的情况下, 银行的期望利润可以表达为

(1) 当 $\mathrm{q} \leq(\mathrm{a}-\mathrm{c}) \mathrm{q}_{0} / \mathrm{c}(1+\mathrm{r})$ 时, 则 $E\left[\Pi_{B}(D)\right]=c q r$, 此时由于企业的守信概率为 1 , 银行可获取贷 款利息期望收益。

(2)当 $\mathrm{q}>(\mathrm{a}-\mathrm{c}) \mathrm{q}_{0} / \mathrm{c}(1+\mathrm{r})$ 时, 则 $E\left[\Pi_{B}(D)\right]=\min \left[a q_{0}-\int_{0}^{q_{0}}(a-b) F(x) d x-c q-d q_{0}, c q(1+r)\right]$, 此时由于企 业经营不善, 一旦出现违约, 银行需要通过处置质押存货的方式来化解损失。

\section{3. 建立风险准备金池后的信贷模型分析}

文章第 2 部分主要基于供应链的视角，利用报童模型对进口电子商务企业的销售和采购 策略进行分析, 得出了存货质押融资违约的临界点。在实际工作中, 企业由于缺乏足额有效 抵质押物, 且目前保税仓存货质押融资还存在以下几个问题：一是企业违约银行在处置货物 时需征得当地海关的许可, 而各地海关对此融资方式的态度并不一致, 因此此模式并未在全 国进行推广; 二是各大商业银行的风险偏好程度高低不一, 一般来说四大行为追求稳健经营 对于这类新兴行业的创新业务并不十分认可, 往往是一些中小型商业银行更看重利润回报而 追求风险, 此外地方性银行为了配合完成政府招商引资任务而对此类业务刻意为之, 收费较 高并且对于抵质押物的折扣系数较高。因此并未在完全意义上解决中小型进口电子商务企业 融资难和融资贵等问题。本节主要引入建立进口电子商务企业协会, 并由政府增信的模式, 解决部分企业资信不够且抵质押物不足的融资难问题, 和部分企业虽然能够提供足额抵质押 物但融资利率较高的融资贵问题。

\section{1 基本假定}

\section{1 .1 政府增信模式的基本假定}

目前政府增信模式在各大商业银行的创新实践中屡试不爽，它主要在整合了商业银行、 政府财政引资以及中小企业团体之间多项信用资源的基础上, 建立了较为有效的风险控制机 制及完善的组织架构。这一业务模式的现实意义在于：一是企业申请融资时只需提交少量的 抵质押物, 解决了申请传统信贷时抵质押物不足的困难; 此外企业只需缴纳少量的风险铺底 资金, 较通过担保机构或小贷公司融资而言, 融资成本大幅降低; 二是政府以财政补贴的形 式出资提供担保, 有利于符合产业发展导向的企业发展。且财政资金参与担保不仅担保信誉 度高, 且能够发挥一定的杜杆作用, 较直接下发财政补贴的形式而言更能支持地方优势产业 的发展; 三是较传统的银行信贷增加了在政府在初期对企业的遴选, 向银行推荐资质优良的 进口电子商务企业, 把好第一道关, 过滤一部分资质不良的企业。此外, 银行的贷款更加小 额化, 在风险分散的情况下利润得到提升; 四是由于加入了政府的增信, 对于银行来说, 企 业的风险价值系数降低从而使得银行风险期望收益降低, 因此银行可为企业提供更低利率的 贷款。

\section{1 .2 参数的基本假定}

本节在银行与跨境电子商务企业之间引入了政府，跨境电子商务协会中的企业与政府共 同出资建立了风险准备金池，假设市场上存在 $\mathrm{n}$ 家风险中性且完全理性的企业加入跨境电子 商务协会, 入会企业缴纳不低于贷款额比例 $\alpha(0<\alpha<1)$ 的风险铺底金, 并向银行提供市场价值 
不低于贷款比例 $\beta(0<w<\beta<1)^{\circledR}$ 的抵质押物申请融资。各家企业均有正常的经营 ${ }^{\circledR}$, 且都在单一 销售季节内销售, 采购数量为 $\mathrm{q}, \mathrm{D}$ 是随机需求, $\bar{D}$ 是平均需求, $\mathrm{F}(\mathrm{x})$ 为需求分布函数,

$F(x)=P(D<x), f(x)$ 为需求概率密度函数, $f(x)=F^{\prime}(x)$, 在单位销售季节结束时未销售完的产品 只能以低于成本的价格促销。采购成本为 $\mathrm{c}$ 的商品, 采购量为 $\mathrm{q}$, 销售价格为 $\mathrm{a}$, 促销价格为 $b$, 则 $a>c>b$ 。货物的单位储存费用为 $s$, 进口电子商务企业自有初始资金为 $C$, 将初始存货 $\mathrm{q}_{0}$ 作为质押向银行申请融资, 贷款利率为 $\mathrm{r}^{*}(\mathrm{r} *<\mathrm{r})$, 存款利率为 0 , 银行根据存货的进价作为 参考价格给予贷款 $\beta c q_{0}$, 企业利用贷款再向供应商采购 $\mathrm{q}^{*}\left(\mathrm{q}<\mathrm{q}^{*}<\mathrm{q}_{0}\right)$ 单位的货物, 则质押率 $\beta$ 可以表示为 $\mathrm{q} * / \mathrm{q}_{0}$ 。政府出资 $\mathrm{F}$ 作为企业融资的保证金, 一旦加入跨境电子商务协会的企业违 约, 它将遭受成本为 $\mathrm{Z}$ 的代价 ${ }^{\ominus}$, 银行将从风险准备金池中得到补偿, 补偿的顺序为先用企业 的风险铺底金，其次处置企业的抵质押物，最后动用政府的保证金。

\section{2 理论模型构建}

根据上文对基本参数的假定，可分别得出在政府增新模式下，进口电商企业在守信时的 期望利润为: $\Pi_{1}^{E^{\prime}}\left(D^{*}\right)=(a-c) \min \left\{D^{*}, q_{0}+q^{*}\right\}+(b-c) \max \left\{0, q_{0}+q^{*}-D^{*}\right\}-c q^{*}\left(1+r^{*}+\alpha\right)-s\left(q_{0}+q^{*}\right)$, 银行 的期望利润为: $\Pi_{1}^{B^{\prime}}\left(D^{*}\right)=c q^{*} r^{*}$; 进口电商企业在违约时的期望利润为:

$\Pi_{2}^{E^{\prime}}\left(D^{*}\right)=(a-c) \min \left\{\max \left[D^{*}-q_{0}, 0\right], q^{*}\right\}+(b-c) \max \left\{0, q^{*}-\max \left[D^{*}-q_{0}, 0\right]\right\}-s\left(q_{0}+q^{*}\right)-c q^{*} \alpha$, 银行的期望 利润为: $\Pi_{2}^{B^{\prime}}\left(D^{*}\right)=\min \left[a \min \left(D^{*}, q_{0}\right)+b \max \left(q_{0}-D^{*}, 0\right)-q^{*}(c-\alpha)-d q_{0}+F, c q^{*}\left(1+r^{*}\right)\right]$

命题 5: 两种模式项下，由于政府增信模式项下企业提供抵质押物的抵质押率升高，相 应的贷款金额增大，能够采购的货物增多。

证明：为保证信贷资金的安全性，则须 $\mathrm{w} \geq \mathrm{q}(1+\mathrm{r}) / \mathrm{q}_{0}, \quad \beta \geq \mathrm{q} *\left(1+\mathrm{r}^{*}\right) / \mathrm{q}_{0}$ 。

命题 6 : 在市场需求 $\mathrm{D}^{*}<\mathrm{D}^{*}$ 时, 企业会选择违约, 此时银行不宜提供贷 款, $D^{*^{\prime}}=\frac{c q(1+r)-(b-c) q_{0}}{(a-b)}$ 。

证明:

$$
\begin{aligned}
& \Pi_{1}^{E^{\prime}}\left(D^{*}\right)-\Pi_{2}^{E^{\prime}}\left(D^{*}\right)=(a-b) D^{*}+(b-c) q_{0}-c q^{*}\left(1+r^{*}\right)<0 \\
& D^{*}<\frac{c q^{*}\left(1+r^{*}\right)-(b-c) q_{0}}{(a-b)}
\end{aligned}
$$

命题 7: 在政府增信模式下，在市场需求 $\mathrm{D} *>\mathrm{D} *$ ”时，进口电商企业和银行双方的期望收 益不受市场需求的影响而变化 $D^{*} "=(1+\beta) q_{0}$ 。

命题 8: 在政府增信模式下，市场需求 $\mathrm{D}>\mathrm{D}$ ”时，如果 $\mathrm{q}^{*} \leq(\mathrm{a}-\mathrm{c}) \mathrm{q}_{0} / \mathrm{c}\left(1+\mathrm{r}^{*}\right)$, 则企业会守信; 当 $\mathrm{q}^{*}>(\mathrm{a}-\mathrm{c}) / \mathrm{c}\left(1+\mathrm{r}^{*}\right)$ 时, 企业会违约, 此临界点和市场需求无关。

推论 3: 在政府增信模式下，企业的期望利润可以表达为

(1)当 $\mathrm{q}^{*} \leq(\mathrm{a}-\mathrm{c}) \mathrm{q}_{0} / \mathrm{c}\left(1+\mathrm{r}^{*}\right)$ 时, 则

$$
E\left[\Pi_{E}^{\prime}\left(D^{*}\right)\right]=(a-c)\left(q_{0}+q^{*}\right)-\int_{0}^{q_{0}+q^{*}}(a-b) F(x) d x-c q^{*}\left(1+r^{*}+\alpha\right)-s\left(q_{0}+q^{*}\right)
$$

此时企业守信的期望收益大于违约的期望收益，理性的企业会选择守信，银行可为企业 提供融资。

(2)当 $\mathrm{q}^{*}>(\mathrm{a}-\mathrm{c}) \mathrm{q}_{0} / \mathrm{c}\left(1+\mathrm{r}^{*}\right)$ 时, 则

$$
E\left[\Pi_{E}^{\prime}\left(D^{*}\right)\right]=-\int_{q_{0}}^{q_{0}+q^{*}}(a-b) F(x) d x-s\left(q_{0}+q^{*}\right)-c q^{*} \alpha
$$

此时企业守信的期望收益小于违约的期望收益，银行应加强对企业经营的关注，防范风 险。

推论 4: 在政府增信模式下，银行的期望利润可以表达为

(1) 当 $\mathrm{q}^{*} \leq(\mathrm{a}-\mathrm{c}) \mathrm{q}_{0} / \mathrm{c}\left(1+\mathrm{r}^{*}\right)$ 时, 则 $E\left[\Pi_{B}^{\prime}\left(D^{*}\right)\right]=c q^{*} r^{*}$, 此时企业的守信概率为 1 , 银行可获取贷 款利息收入，但 $E\left[\Pi_{B}^{\prime}\left(D^{*}\right)\right]<E\left[\Pi_{B}\left(D^{*}\right)\right]$ 。

${ }^{\circledR}$ 此时引入政府增信, 抵质押率升高。

初衷并不是纯粹注册一个空壳公司骗取银行贷款。

๑这种成本可以理解为企业的信用、声誉受到了损失, 以后不能在银行贷款。 
(2)当 $\mathrm{q}^{*}>(\mathrm{a}-\mathrm{c}) \mathrm{q}_{0} / \mathrm{c}\left(1+\mathrm{r}^{*}\right)$ 时, 则

$E\left[\Pi_{B}^{\prime}\left(D^{*}\right)\right]=\min \left[a q_{0}-\int_{0}^{q_{0}}(a-b) F(x) d x-q^{*}(c-\alpha)-d q_{0}+F, c q^{*}\left(1+r^{*}\right)\right]$, 此时企业经营不善, 违约概 率上升，银行需要处置部分质押存货并动用风险准备金池中的资金来补偿风险损失。

按照上文思路，证明易得，略。但在政府增信条件下，银行对风险的处置和化解能力增 强，首先由风险铺底资金和政府保证金对风险进行补偿，不足部分再处置抵质押物，况且抵 质押率较纯存货质押授信模式项下要低, 因此这一融资模式既可以降低企业违约的风险隐患 又能提高企业获取融资的概率, 对于银行和企业来说是双赢。

推论 5: 当 $\mathrm{q} \leq(\mathrm{a}-\mathrm{c}) \mathrm{q}_{0} / \mathrm{c}(1+\mathrm{r}), \mathrm{q}^{*} \leq(\mathrm{a}-\mathrm{c}) \mathrm{q}_{0} / \mathrm{c}\left(1+\mathrm{r}^{*}\right), \quad \alpha<\alpha^{\prime}$ 时, 进口电子商务企业会选择加入 协会缴纳入会费并利用政府增信获得融资; 当 $(\mathrm{a}-\mathrm{c}) \mathrm{q}_{0} / \mathrm{c}(1+\mathrm{r})<\mathrm{q}, \mathrm{q}^{*} \leq(\mathrm{a}-\mathrm{c}) \mathrm{q}_{0} / \mathrm{c}\left(1+\mathrm{r}^{*}\right), \alpha<\alpha^{\prime \prime}$ 时, 进口电子商务企业会选择加入协会缴纳入会费并利用政府增信获得融资; 当 $(a-c) q_{0} / c(1+r)<q$, $(\mathrm{a}-\mathrm{c}) \mathrm{q}_{0} / \mathrm{c}\left(1+\mathrm{r}^{*}\right)<\mathrm{q}^{*}$ 时, 进口电子商务企业不会加入协会, 选择保税仓存货质押融资并且违约。 其中 $\alpha^{\prime}=\frac{\left[(a-2 c-s)\left(q^{*}-q\right)-c\left(q^{*} r^{*}-q r\right)-\int_{q_{0}+q}^{q_{0}+q^{*}}(a-b) F(x) d x\right]}{c q^{*}}$,

$$
\alpha^{\prime \prime}=\frac{(a-c-s)\left(q^{*}+q_{0}\right)+s\left(q+q_{0}\right)-\int_{q_{0}+q}^{q_{0}+q^{*}}(a-b) F(x) d x-\int_{0}^{q_{0}}(a-b) F(x) d x}{c q^{*}}-\left(1+r^{*}\right) \text { 。 }
$$

证明：与第二节中企业的期望利润进行比较可得

$(1) \mathrm{q}<\mathrm{q} * \leq(\mathrm{a}-\mathrm{c}) \mathrm{q}_{0} / \mathrm{c}(1+\mathrm{r})$ 时,

$$
\begin{aligned}
\Delta E= & (a-c)\left(q_{0}+q^{*}\right)-\int_{0}^{q_{0}+q^{*}}(a-b) F(x) d x-c q^{*}\left(1+r^{*}+\alpha\right)-s\left(q_{0}+q^{*}\right)- \\
& {\left[(a-c)\left(q_{0}+q\right)-\int_{0}^{q_{0}+q}(a-b) F(x) d x-c q(1+r)-s\left(q_{0}+q\right)\right] } \\
= & (a-2 c-s)\left(q^{*}-q\right)-c\left(q^{*} r^{*}-q r\right)-\int_{q_{0}+q}^{q_{0}+q^{*}}(a-b) F(x) d x-c q^{*} \alpha \\
& >0 \\
\alpha< & \frac{\left[(a-2 c-s)\left(q^{*}-q\right)-c\left(q^{*} r^{*}-q r\right)-\int_{q_{0}+q}^{q_{0}+q^{*}}(a-b) F(x) d x\right]}{c q^{*}}
\end{aligned}
$$

(2) $\mathrm{q} \leq(\mathrm{a}-\mathrm{c}) \mathrm{q}_{0} / \mathrm{c}(1+\mathrm{r})<\mathrm{q}^{*} \leq(\mathrm{a}-\mathrm{c}) \mathrm{q}_{0} / \mathrm{c}\left(1+\mathrm{r}^{*}\right)$ 时

$$
\begin{aligned}
& \Delta E=(a-c)\left(q_{0}+q^{*}\right)-\int_{0}^{q_{0}+q^{*}}(a-b) F(x) d x-c q^{*}\left(1+r^{*}+\alpha\right)-s\left(q_{0}+q^{*}\right)- \\
& {\left[(a-c)\left(q_{0}+q\right)-\int_{0}^{q_{0}+q}(a-b) F(x) d x-c q(1+r)-s\left(q_{0}+q\right)\right] } \\
&=(a-2 c-s)\left(q^{*}-q\right)-c\left(q^{*} r^{*}-q r\right)-\int_{q_{0}+q}^{q_{0}+q^{*}}(a-b) F(x) d x-c q^{*} \alpha \\
&> 0 \\
& \alpha< {\left[(a-2 c-s)\left(q^{*}-q\right)-c\left(q^{*} r^{*}-q r\right)-\int_{q_{0}+q}^{q_{0}+q^{*}}(a-b) F(x) d x\right] } \\
& c q^{*}
\end{aligned}
$$

(3) $(\mathrm{a}-\mathrm{c}) \mathrm{q}_{0} / \mathrm{c}(1+\mathrm{r})<\mathrm{q}<\mathrm{q}^{*} \leq(\mathrm{a}-\mathrm{c}) \mathrm{q}_{0} / \mathrm{c}\left(1+\mathrm{r}^{*}\right)$ 时

$$
\begin{aligned}
\Delta E & =(a-c)\left(q_{0}+q^{*}\right)-\int_{0}^{q_{0}+q^{*}}(a-b) F(x) d x-c q^{*}\left(1+r^{*}+\alpha\right)-s\left(q_{0}+q^{*}\right)-\left[-\int_{q_{0}}^{q_{0}+q}(a-b) F(x) d x-s\left(q_{0}+q\right)\right] \\
& =(a-c-s)\left(q^{*}+q_{0}\right)+s\left(q+q_{0}\right)-c q^{*}\left(1+r^{*}\right)-c q^{*} \alpha-\int_{q_{0}+q}^{q_{0}+q^{*}}(a-b) F(x) d x-\int_{0}^{q_{0}}(a-b) F(x) d x \\
& >0
\end{aligned}
$$

(4) $(\mathrm{a}-\mathrm{c}) \mathrm{q}_{0} / \mathrm{c}(1+\mathrm{r})<\mathrm{q} \leq(\mathrm{a}-\mathrm{c}) \mathrm{q}_{0} / \mathrm{c}\left(1+\mathrm{r}^{*}\right)<\mathrm{q}^{*}$ 时

$$
\begin{aligned}
\Delta E & =-\int_{q_{0}}^{q_{0}+q^{*}}(a-b) F(x) d x-s\left(q_{0}+q^{*}\right)-c q^{*} \alpha-\left[-\int_{q_{0}}^{q_{0}+q}(a-b) F(x) d x-s\left(q_{0}+q\right)\right] \\
& >0 \\
\alpha & <\frac{s\left(q-q^{*}\right)-\int_{q_{0}+q}^{q_{0}+q^{*}}(a-b) F(x) d x}{c q^{*}}<0
\end{aligned}
$$

因此, (a-c) $\mathrm{q}_{0} / \mathrm{c}(1+\mathrm{r})<\mathrm{q}<(\mathrm{a}-\mathrm{c}) \mathrm{q}_{0} / \mathrm{c}\left(1+\mathrm{r}^{*}\right)<\mathrm{q}^{*}$ 时, $E\left[\Pi_{E}^{\prime}\left(D^{*}\right)\right]<E\left[\Pi_{E}\left(D^{*}\right)\right]$, 企业会仅选择保税 仓存货质押融资并且违约。

(5) $(\mathrm{a}-\mathrm{c}) \mathrm{q}_{0} / \mathrm{c}(1+\mathrm{r})<(\mathrm{a}-\mathrm{c}) \mathrm{q}_{0} / \mathrm{c}\left(1+\mathrm{r}^{*}\right)<\mathrm{q}<\mathrm{q}^{*}$ 时 


$$
\begin{aligned}
\Delta E & =-\int_{q_{0}}^{q_{0}+q^{*}}(a-b) F(x) d x-s\left(q_{0}+q^{*}\right)-c q^{*} \alpha-\left[-\int_{q_{0}}^{q_{0}+q}(a-b) F(x) d x-s\left(q_{0}+q\right)\right] \\
& >0 \\
\alpha< & \frac{s\left(q-q^{*}\right)-\int_{q_{0}+q}^{q_{0}+q^{*}}(a-b) F(x) d x}{c q^{*}}<0
\end{aligned}
$$

因此, (a-c) $\mathrm{q}_{0} / \mathrm{c}(1+\mathrm{r})<(\mathrm{a}-\mathrm{c}) \mathrm{q}_{0} / \mathrm{c}\left(1+\mathrm{r}^{*}\right)<\mathrm{q}<\mathrm{q}^{*}$ 时, $E\left[\Pi_{E}^{\prime}\left(D^{*}\right)\right]<E\left[\Pi_{E}\left(D^{*}\right)\right]$, 企业会仅选择保税 仓存货质押融资并且违约。

(6) $\mathrm{q}<(\mathrm{a}-\mathrm{c}) \mathrm{q}_{0} / \mathrm{c}(1+\mathrm{r}) \leq(\mathrm{a}-\mathrm{c}) \mathrm{q}_{0} / \mathrm{c}(1+\mathrm{r} *)<\mathrm{q} *$ 时

$$
\begin{aligned}
\Delta E & =-\int_{q_{0}}^{q_{0}+q^{*}}(a-b) F(x) d x-s\left(q_{0}+q^{*}\right)-c q^{*} \alpha-(a-c)\left(q_{0}+q\right)+\int_{0}^{q_{0}+q}(a-b) F(x) d x+c q(1+r)+s\left(q_{0}+q\right) \\
& =\int_{0}^{q_{0}}(a-b) F(x) d x-\int_{q_{0}+q}^{q_{0}+q^{*}}(a-b) F(x) d x+s\left(q-q^{*}\right)+c\left(q+q r-q^{*} \alpha\right)-(a-c)\left(q_{0}+q\right) \\
& >0 \\
\alpha & <\frac{\int_{0}^{q_{0}}(a-b) F(x) d x-\int_{q_{0}+q}^{q_{0}+q^{*}}(a-b) F(x) d x+s\left(q-q^{*}\right)+c(q+q r)-(a-c)\left(q_{0}+q\right)}{c q^{*}}
\end{aligned}
$$

这种情况下较为复杂, 进口电商企业在存货质押模式项下会守信但在政府增信模式下会 违约, 意味着在存货质押模式下会理性经营, 但在政府增信模式下会盲目扩张备货。在现实 中, 由于进口电商企业加入协会后会受到其他成员的监督, 定期也会被政府等进行评级, 一 旦信誉有问题以后很难在这个行业和领域继续经营, 因此违约成本较存货质押模式下高, 两 种融资模式中理性的企业不会选择违约成本高的违约 ${ }^{[13]}$ 。

根据以上的推导结论可以看出, 由于在政府提供增信的情况下，银行的期望风险降低， 可为进口电商企业提供的融资额相较于存货质押模式下更高, 进口电商企业可用此资金更多 的备货，但是这种模式项下进口电商企业会付出像风险铺底资金这一类多余的成本，银行提 高风险控制水平但获得较少的风险收益。

推论 6: 当 $\mathrm{F}>\mathrm{c}\left(\mathrm{q}^{*}-\mathrm{q}\right)-\alpha \mathrm{q}$ 时, 政府增信模式对银行较为有利。

证明: 在企业不违约的情况下, 由于银行分别在两种融资模式下的期望收益分别为 cqr 和 $\mathrm{cq}^{*} \mathrm{r}^{*}$ ，可以通过调整贷款利率和存货质押率来动态调整期望收益; 在企业违约的情况下， 由于银行首要考虑的是如何化解处置风险, 通过处置质押存货或者动用风险准备金池资金及 保证金, 而不是处置限额 ${ }^{[14]}$ 。因此在此情况下, 考虑公式的前一项, 可以明显得出两种融资 模式项下企业违约后银行的期望收益对比： $\Pi_{2}^{B}\left(D^{*}\right)-\Pi_{2}^{B^{\prime}}\left(D^{*}\right)=c\left(q^{*}-q\right)-\alpha q^{*}-F$ ，因此当 $F>c\left(q^{*}-q\right)-\alpha q *$ 时, 政府增信模式对银行比较有利。这一点比较好理解, 由于政府介入后对 企业提供了增信, 产生风险后不仅仅是对企业追偿, 可以优先动用风险铺底资金及保证金这 一“安全垫”。

结论 1: 银行为进口电商企业提供融资时不仅要了解货物的市场需求, 还要对进口电商 企业的历史备货数据及资金用途尽职调查，如果进口电商企业盲目扩张备货，则银行贷款不 良的风险增大。具体表示为在分别在两种模式项下 $\mathrm{D}<\mathrm{D}^{\prime}$ 和 $\mathrm{D}^{*}<\mathrm{D}^{*}$ '时, 企业会选择违约, 此 时为买方市场, 需求小于供给, 企业违约的期望收益始终大于守信时的期望收益, 银行不宜 提供贷款; 当 $\mathrm{D}>\mathrm{D}$ ”和 $\mathrm{D}^{*}>\mathrm{D}^{*}$ ”时, 双方期望收益与市场需求的变化无关, 意味着当市场需 求达到一定程度以上是供给方占优势的卖方市场, 企业的备货量大小及价格因素才会影响不 同决策时的期望收益, 而与市场需求的变化无关; 当 $D>D^{\prime}$ 和 $q>(a-c) q_{0} / c(1+r)$ 时, 货物质押模 式下企业的违约概率增大; 当 $\mathrm{D}^{*}>\mathrm{D}^{*}$, 和 $\mathrm{q}^{*}>(\mathrm{a}-\mathrm{c}) \mathrm{q}_{0} / \mathrm{c}\left(1+\mathrm{r}^{*}\right)$ 时, 政府增信模式项下进口电商企 业违约风险增大，此时企业盲目扩张，会导致违约，银行不宜提供贷款。

结论 2: 只要风险铺底资金的要求不超过一定数额：即 $\mathrm{q} \leq(\mathrm{a}-\mathrm{c}) \mathrm{q}_{0} / \mathrm{c}(1+\mathrm{r})$ 时, $\alpha<\alpha^{\prime}$; $(a-c) q_{0} / c(1+r)<q$ 时， $\alpha<\alpha ” ;$ 理性的进口电商企业往往会选择政府增信模式来获取融资，因为 企业为融资所付出的成本较少，由于质押率的升高获取贷款的金额增加。

结论 3: 政府提供的担保金大于一定数额: 即 $\mathrm{F}>\mathrm{c}\left(\mathrm{q}^{*}-\mathrm{q}\right)-\alpha \mathrm{q}$ 时, 银行采用政府增信模式 为企业融资较为有利。由于政府提供的保证金数量达到银行要求后, 风险也相对可控, 可为 进口电商企业提供的融资额相较于存货质押模式下更高，进口电商企业可用此资金更多的备 
货量。因此这种模式不仅在股份制银行应用较广，在也受到大型国有银行的青睐，例如工商 银行的“银政通”和建设银行的“助保贷”等。在这种模式下, 政府通过出资方式带动了跨境电 商行业的增长, 政银企三方获得三赢。

\section{4. 数值模拟}

上文站在进口电商企业用款备货的角度分析了融资守信和违约的决策选定，可以为银行 贷款尽职调查给出一定的建议，在防范风险的条件下，获取期望收益最大化，但相关公式推 论较为复杂, 结论并不直观, 因此本节以数值模拟的方式来做实验, 验证进口电商企业在需 求不确定的情况下备货多少从而影响不同融资方式项下的守信违约策略。

\section{1 存货质押授信模式下数值模拟}

假设在一个周期内进口电商企业采购货物的单位采购成本 $\mathrm{c}=80$, 单位销售价格 $\mathrm{a}=100$, 如果未销售完以 $b=50$ 的单位价格进行促销, 货物的单位储存费用 $s=1$, 初始存货量 $\mathrm{q}_{0}$ 固定为 10000 , 在存货质押授信模式项下银行的贷款利率 $\mathrm{r}=4 \%$, 质押率 $\mathrm{w}=0.5$, 进口电商企业如果 违约后银行对于货物的单位处置费用 $\mathrm{d}=0.8$, 以上为固定参数。对市场需求 $\mathrm{D}$ 和 $\mathrm{D} *{ }^{\circledR}$ 取几组 不同数值做实验, 考察进口电商企业订货量和期望收益随进口电商企业备货的变化, 从而得 出银行对进口电商企业在存货质押融资模式下违约或守信的应对决策。

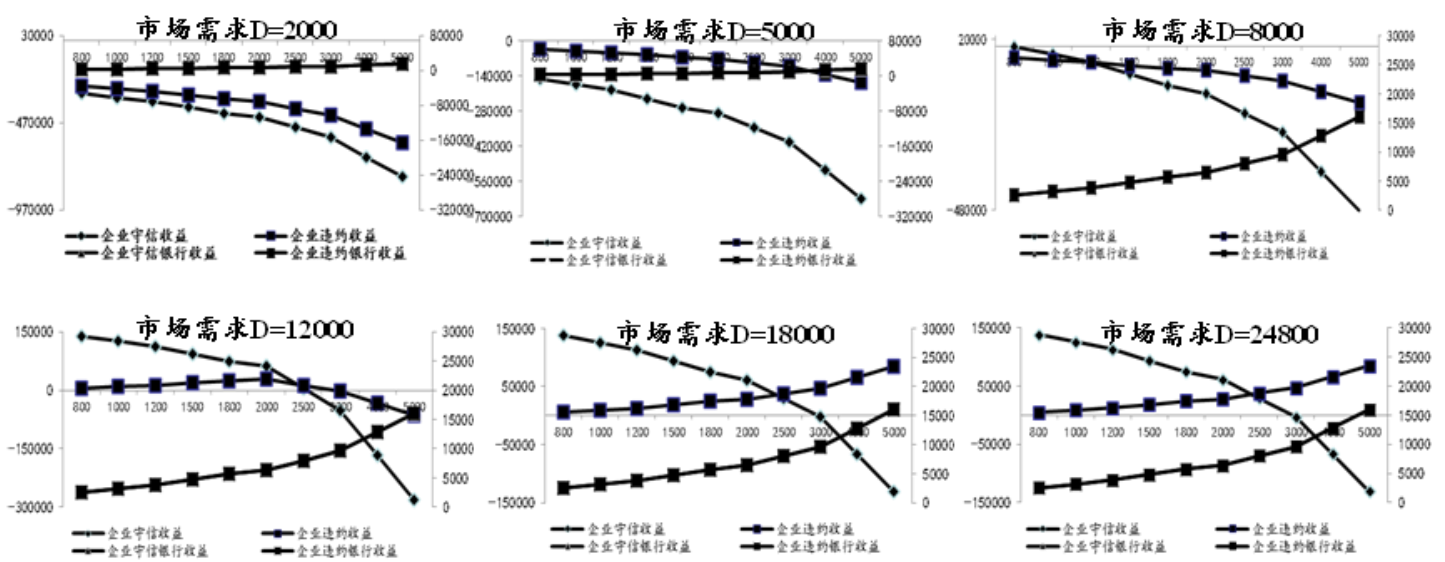

图 2 银行提供存货质押模式项下融资双方的期望收益与电商备货量的关系

图 2 描述了银行在提供了存货质押模式项下关于进口电商企业守信或者违约双方的期望 收益, 其中进口电商企业和银行的期望收益曲线分别由纵坐标轴 1 和 2 表示, 可以得出: 首 先, 在进口电商企业守信的情况下, 银行的期望收益是随备货量多少逐步上升的, 但由于质 押率导致融资金额有上限, 银行的期望收益上限为 wcqor; 其次, 随着市场需求的减少, 进口 电商企业的违约概率上升, 从前两张图中可见，进口电商企业选择违约时的期望收益始终高 于选择守信时的期望收益, 从而验证了命题 2 的结论; 然后, 随着进口电商企业备货量的上 升, 进口电商企业的违约概率逐步增大, 当备货量 $\mathrm{q}=(\mathrm{a}-\mathrm{c}) \mathrm{q}_{0} / \mathrm{c}(1+\mathrm{r})$ 的时候, 进口电商企业的 理性备货量达到最大, 超过此临界点后进口电商企业选择违约, 临界点不受市场需求的影响; 最后, 当市场需求 $\mathrm{D}>(1+\mathrm{w}) \mathrm{q}_{0}$ 时, 进口电商企业的选择不影响双方的期望收益, 具体表现为 最后 2 张图的走势基本相同, 验证了命题 3, 这种情况下说明是需求大于供给的卖方市场, 企业对备货量影响收益的考虑大于市场的需求，仅仅会比较两种决策下自己的期望收益最大 化，当备货量超过临界值时违约收益更大，企业选择违约，银行应审慎管理融资风险。

\footnotetext{
『1 以下对于两种融资模式下的市场需求取同样的值, 即两种模式实在同样的市场需求下, 便于进行对比。
} 


\section{2 政府增信模式下数值模拟}

对货物的单位采购成本 $\mathrm{c}$, 单位销售价格 $\mathrm{a}$, 单位促销价格 $\mathrm{b}$, 单位储存费用, 初始存货 量 $\mathrm{q}_{0}$, 以及存货质押授信模式项下银行的贷款利率 $\mathrm{r}$ 和质押率 $\mathrm{w}$, 违约后银行的单位处置费 用 $\mathrm{d}$ 固定和上文一致。政府出资 $\mathrm{F}=10000$, 质押率 $\beta=0.7$ 为固定，本节在不同市场需求条件 下，分别考察政府增信模式项下银企双方期望收益与贷款利率 $r^{*}$ 、入会费 $\alpha$ 及进口电商企业 采购货物数量之间的关系, 从而得出进口电商企业分别在两种融资模式下违约或守信的决策。
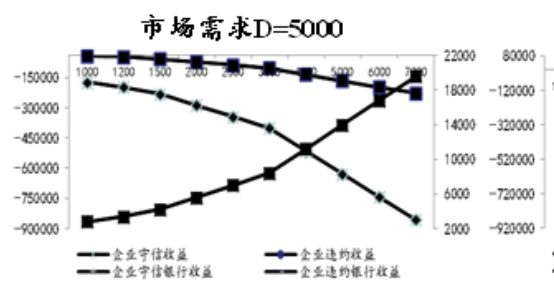

市场需求 $\mathrm{D}=10000$

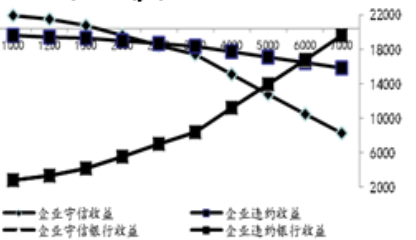

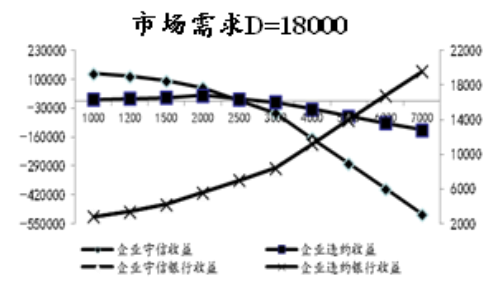

图 3 银行提供政府增信方式项下融资双方的期望收益与电商备货量的关系

图 3 选取了入会费 $\alpha=0.2 \%$, 贷款利率 $\mathrm{r}^{*}=0.035$, 的时候, 市场需求不同条件下，进口电 商企业与银行的期望收益随进口电商企业备货量多少的变化。和存货质押模式项下的结论大 体类似：在进口电商企业守信的情况下，银行的期望收益是随备货量多少逐步上升的，但期 望收益上限为 $\beta c q_{0}$ r; 当 $\mathrm{D}<\mathrm{D}$ ’时, 进口电商企业会选择违约, 此时银行应注重风险防范; 当 $\mathrm{D}>\mathrm{D}$ ”时, 当备货量 $\mathrm{q}=(\mathrm{a}-\mathrm{c}) \mathrm{q}_{0} / \mathrm{c}\left(1+\mathrm{r}^{*}\right)$ 的时候, 为进口电商企业的违约临界点, 这和图 2 的结 果一起验证了结论 1 .

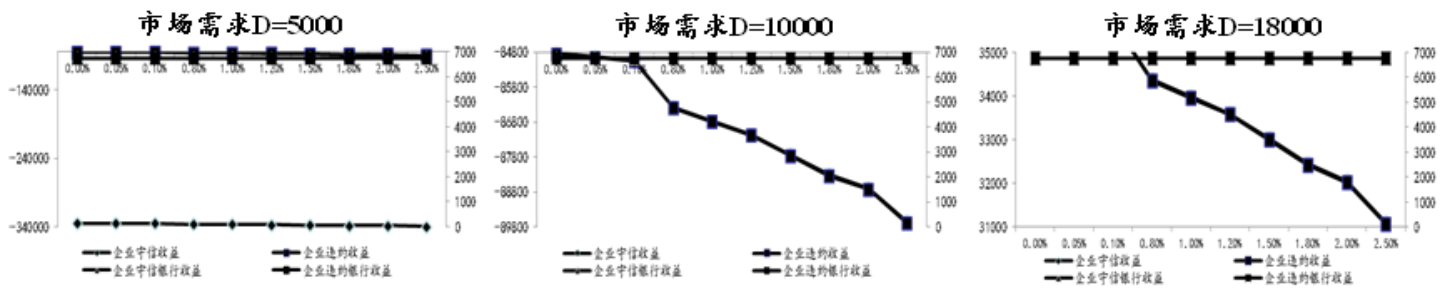

图 4 银行提供政府增信方式项下融资双方的期望收益与电商入会费的关系

图 4 选取了进口电商备货量的临界值 $\mathrm{q}^{*}=2415$, 贷款利率 $\mathrm{r}^{*}=0.035$ 的时候, 市场需求不 同条件下, 进口电商企业与银行的期望收益随进口电商企业入会费多少的变化。当 $\mathrm{D}<\mathrm{D}$ 即市 场需求过小时, 进口电商企业会选择违约, 此时银行应注重风险防范; 进口电商的期望收益 与入会费的高低呈反比。
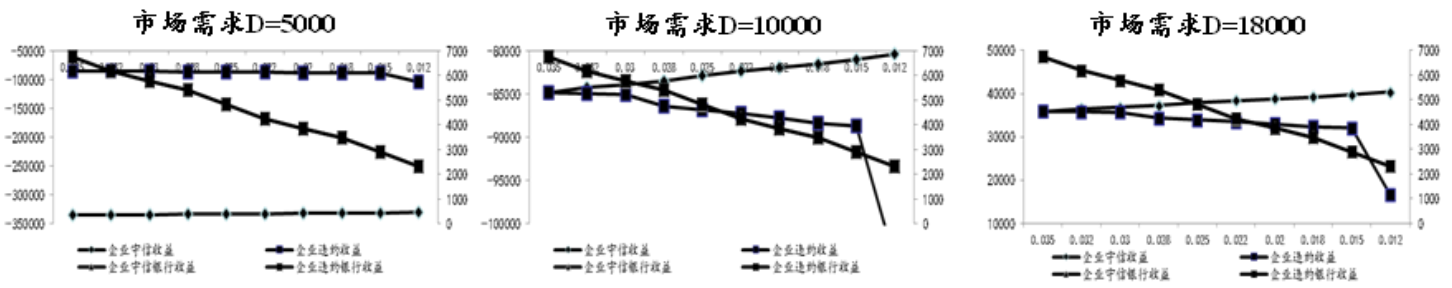

图 5 银行提供政府增信方式项下融资双方的期望收益与银行贷款利率的关系

图 5 选取了进口电商备货量的临界值 $\mathrm{q}^{*}=2415$, 入会费 $\alpha=0.2 \%$ 的时候, 市场需求不同条 件下，进口电商企业与银行的期望收益随银行贷款利率多少的变化。与上文类似，当市场需 求过大时, 进口电商企业的守信概率增大; 银行和进口电商企业的期望收益分别与贷款利率 呈反比和正比, 进一步, 可以从图中看出随着市场需求的增大, 进口电商企业守信条件下随 着贷款利率的下降上升的速度加快, 显然, 在市场需求过于旺盛的时候, 银行可加大对于企 业的融资支持力度，使得银企之间获得双赢。 


\section{3 两种模式的比较}

上文通过总结进口电子商务企业在银行融资的两种模式，一是通过银行进口电子商务企 业的存量货物进行评估质押融资对盘活了企业的存款固定资产，为资质良好和违约概率低的 优质中小型进口电子商务企业提供了融资支持并扩大规模的机会，解决了融资难问题。二是 成立跨境电子商务企业协会，并通过引入政府财政资金对其增信，从而提高了抵质押存货的 抵质押率，降低了企业的融资成本，使优质中小型进口电子商务企业获得银行的信贷支持的 成本降低, 并通过数值模拟检验了部分命题和结论。如上文所述, 银行经营风险获取风险收 益 ${ }^{[15]}$, 在企业不违约的情况下, 由于银行分别在两种融资模式下的期望收益分别为 cqr 和 $\mathrm{cq}^{*} \mathrm{r}^{*}$, 由于政府增信模式下银行的风险相对可控, 因此 $\mathrm{r}^{*}<\mathrm{r}$; 也因此质押率 $\beta>\mathrm{w}$, 在企业守 信模式下可动态调节这两项指标来获取风险收益。在企业预期违约的情况下，按照之前的分 析, 政府增信模式下银行风险处置水平更高, 因此本节主要用数值模拟的方式来检验上述结 论。

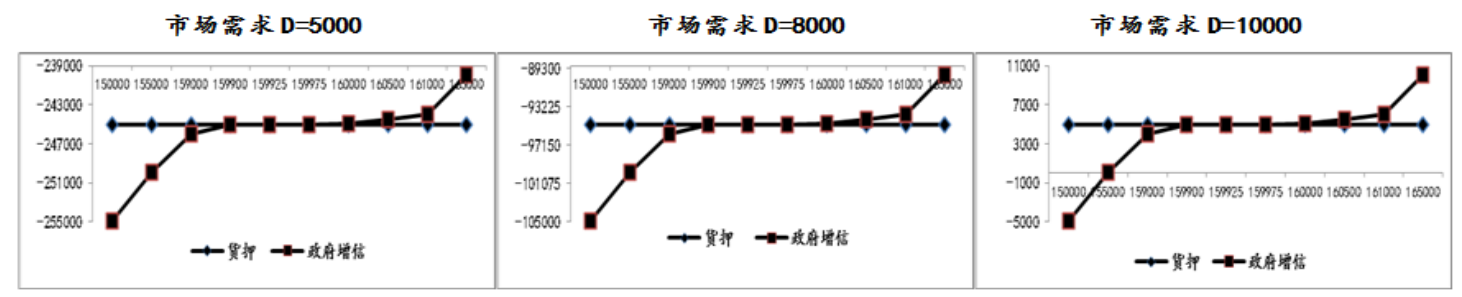

图 6 企业银行提供政府增信方式项下融资双方的期望收益与银行贷款利率的关系

图 6 选取了存货质押授信模式和政府增信模式下质押率分别为 0.5 和 0.7 , 贷款利率分别 为 $4 \%$ 和 $3.5 \%$ ，入会费 $\alpha=0.5 \%$ ，企业获取贷款资金后不管市场需求的大小全额用来备货的情 况下，各设定了 3 组不同市场需求来验证银行在企业违约情况下的期望收益随政府出资额的 变化。可以看出随着市场需求的增加, 两种融资模式下银行的期望收益都在提升, 存货质押 授信项下呈一条直线，但政府增信模式下随着政府出资保证金的增加，银行的期望收益逐步 上升, 当达到一个临界点 $\mathrm{F}>\mathrm{c}\left(\mathrm{q}^{*}-\mathrm{q}\right)-\alpha \mathrm{q}$ 的时候超过了存货质押授信下的期望收益, 这验证了 结论 2 和结论 3 。

\section{5. 结论及启示}

\section{1 结论}

首先，在银行的视角总结了对进口电子商务企业融资的两种方式，一是通过银行进口电 子商务企业的存量货物进行评估质押融资对盘活了企业的存款固定资产; 二是成立跨境电子 商务企业协会，并通过引入政府财政资金对其增信，从而提高了抵质押存货的抵质押率，降 低了企业的融资成本; 其次, 在两种融资方式下都引入了报童模型对进口电子商务企业在保 税进口模式项下的备货策略进行分析，得出了在需求不确定的情况下，进口电子商务企业分 别在守信和违约策略下的期望收益, 得出了进货量的大小、入会费高低对企业选择融资模式 及守信影响的临界值; 然后, 对两种融资方式进行比较, 发现了入会费和政府出资额变化对 于企业选择融资模式及守信概率的影响, 为银行提供融资和风险防范提出了建议; 最后, 通 过数值模拟的方法对以上的结论进行了验证。

\section{2 启示}

通过上文的分析可以得出，目前在我国普遍存在的中小企业融资难和融资贵的问题同样 影响着近年来兴起的跨境电子商务行业。由于中小型进口电子商务行业在刚刚起步之时并没 有银行看重的信用记录, 银企之间信息严重不对称, 因此银行担心出现融资风险, 往往采取“抵 押担保至上”的信贷倾向 ${ }^{[16]}$ 。对于进口电子商务企业来说，轻资产、利润薄的特征使其受到银 
行的信贷约束，融资难、融资贵的问题尤为突出。但对于进口电子商务行业来说，近年来国 家出台一系列政策和文件大力支持发展, 各地政府也在想方设法和银行合作创新融资方式。 因此本文基于盘活进口电子商务企业存货、成立协会并采取政府增信的方式创新融资模式。 本文的理论分析对进口电子商务企业在保税进口模式项下的备货及融资策略进行了较为详尽 的分析, 对缓解中小型进口电子商务企业融资难和融资贵的难题具有一定的现实意义, 并为 银行金融创新支持进口电子商务企业发展提供了新思路。

\section{References}

[1] Jin xuejun and Lu shaoji. Financing platform innovation in Zhejiang -- solving the financing difficulties of SMES with the help of government and market [M]. Hangzhou: Zhejiang University Press,2010.

[2] Guo na. Government? The market? Who is more effective - the research on the effectiveness of financing difficulty solving mechanism for small and medium-sized enterprises [J]. Financial Research, 2013(3):194-206.

[3] Shen Hongming. Financing and enterprise credit of private SMES under the condition of transition economy [J]. Management World, 2006(10):162-163.

[4] Xu zhong and Zou chuanwei. Allocation of bank internal loan approval authority and design of incentive mechanism under the framework of hard information and soft information -implications for SMES' financing [J]. Financial Research,2010(8):1-15.

[5] Xie weimin and Fang hongxing. Financial development, financing constraints and enterprise R\&D investment [J]. Financial Research, 2011 (5): 171-183.

[6] Douglas M. The Eight Essential Supply Chain Management processes[J]. Supply Chain Management Review,2004(8)6:18-26.

[7] Zhan jizhou and Lu rui. Research on selection strategy of supply chain financing mode under the constraint of retailer purchasing funds [J]. Journal of Management Engineering,2016(7).

[8] Lu Qihui, Yao Jiaxi and Zhou Weihua. Selection of stock pledge financing business model based on EOQ model [J]. China Management Science, 2016(1).24.

[9] Leor A. Klapper. The Role of "Reverse Factoring"in Supplier Financing of Small and Medium Sized Enterprises[R]. World Bank,2004(4):102-103.

[10] Song Jianjiang. Government credit enhancement, loan efficiency and economic growth [J]. Financial Development Review,2016.3.

[11] Wang hui,Deng Xiaomei, Yang Weihua and Feng ke. Analysis of evolution and stability conditions of sme credit reguarantee system [J]. China Management Science,2016(7).24.

[12] Zhu Wengui, Zhu Daoli and Xu ju. Pricing model of inventory pledge financing service under delayed payment mode [J]. Theory and Practice of System Engineering,2007(12).

[13] Zhao yue and Tan Zhibo. E-commerce, bank credit and SME financing -- a theoretical model based on information economics [J]. Financial Research, 2012(7):99-112.

[14] Niu Ximing. Theoretical research on loan risk management of China's commercial Banks [J]. Economic research, 1998(3):58-65.

[15] Huang Xiaowei, Guo min and Li Yinghua. Research on dynamic correlation between banking competition and risk in the process of interest rate liberalization $[\mathrm{J}]$. Quantitative Economics and Technical Economics Research, 2016(1):75-91. 
[16] Wang Xiao and Zhang Jie. Bank credit rationing and SME loan -- a theoretical model of endogenous collateral and enterprise size [J]. Economic research,2003(7). 